\title{
STRUKTUR DAN VEGETASI TUMBUHAN BAWAH PADA TEGAKAN PINUS DI RPH KALIRAJUT DAN RPH BATURRADEN BANYUMAS
}

\author{
NADia DeSTARANTI, SULISTYANI, Edy YANi
}

Fakultas Biologi, Universitas Jenderal Soedirman, Jalan dr. Suparno 63 Purwokerto 53122

\section{A B S T R A C T}

A study on the undergrowth vegetation within the pine woods (Pinus merkusii) stands conducted in RPH Kalirajut and RPH Baturraden. This study aimed to find out the composition of the shrubs of the pine woods stands on those two sites with different altitude and to figure out the similarity of the herbs of the pine woods stands on those two locations with the different height. This study applied quadrat sampling technique, using 30 units of $2 \times 2 \mathrm{~m}$ quadrats divided into ten sub-transects along the main transect. We measured environmental factors including elevation, temperature, light intensity, and $\mathrm{pH}$ of the soil. We found undergrowth vegetation in RPH Kalirajut comprised of 32 species belonging to 20 families, dominated by Ottochloa nodosa, Oplismenus compositus, and Cynodon dactylon On the other site, we found undergrowth vegetation in RPH Baturraden composed of 19 species belonging to 20 families and dominated by Wedelia trilobata, Paspalum conjugatum, and Clidemia hirta. The similarity of the herbs vegetation measured of those two sites was $30.85 \%$ or $69.15 \%$ different.

KEY WORDS: pinewoods, undergrowth, elevation

Penulis korespondensi: NADIA DESTARANTI | email: nadiadestar@gmail.com

\section{PENDAHULUAN}

Hutan merupakan suatu ekosistem yang terdiri dari berbagai jenis tumbuh-tumbuhan dan hewan. Masyarakat tumbuh-tumbuhan dalam suatu ekosistem hutan memiliki hubungan erat satu sama lain dengan lingkungannya. Menurut Soerianegara \& Indrawan (2005), hutan juga memiliki peran sebagai tempat tinggal dan makanan bagi berbagai jenis fauna yang hidup di dalamnya. Populasi tumbuhan dan hewan di dalam hutan membentuk masyarakat yang saling berkaitan erat satu sama lain dengan lingkungan sekitarnya. Oleh karena itu, hutan dipandang sebagai suatu sistem ekologi atau merupakan ekosistem yang sangat berguna bagi kehidupan manusia.

Backer (1973) menyatakan bahwa di dalam hutan terdapat berbagai keanekaragaman hayati, baik satwa liar maupun tumbuhan. Dari keanekaragaman sumber daya hayati di hutan tersebut tidak hanya terbatas pada jenis tumbuhan berkayu, namun juga ditumbuhi oleh beranekaragam tumbuhan bawah (ground cover/ undergrowth) yang memiliki keanekaragaman jenis yang tinggi. Tumbuhan bawah merupakan suatu jenis vegetasi dasar yang terdapat di bawah tegakan hutan kecuali anakan pohon. Tumbuhan bawah meliputi rumput-rumputan, herba, semak belukar dan pakupakuan (Yuniawati, 2013).

Tumbuhan bawah dalam susunan stratifikasi menempati lapisan D yang memiliki tinggi $<4,5 \mathrm{~m}$ dan diameter batangnya sekitar $2 \mathrm{~cm}$ (Windusari et al., 2012). Jenis tumbuhan bawah bersifat annual, biennial, perennial serta pola penyebarannya dapat terjadi secara acak, berumpun/berkelompok dan merata. Nirwani (2010) melaporkan bahwa tumbuhan bawah yang ditemukan umumnya dari anggota suku Poaceae, Cyperaceae, Araceae, Asteraceae, dan pakupakuan. Keberadaan tumbuhan bawah di lantai hutan dapat berfungsi sebagai penahan pukulan air hujan dan aliran permukaan sehingga meminimalkan bahaya erosi. Selain itu, vegetasi tumbuhan bawah berperan penting dalam ekosistem hutan dan menentukan iklim mikro (Hilwan et al., 2013).

Struktur dan komposisi vegetasi tumbuhan dipengaruhi oleh komponen ekosistem lainnya yang saling berinteraksi, sehingga vegetasi yang tumbuh secara alami merupakan hasil interaksi berbagai faktor lingkungan. Struktur vegetasi adalah suatu organisasi individu-individu di dalam ruang yang membentuk suatu tegakan (Mueller \& Ellenberg, 1974). Sedangkan komposisi hutan merupakan jenisjenis penyusun yang menempati vegetasi di suatu tempat (Wirakusuma, 1980).

Perbedaan struktur dan komposisi pada setiap strata tumbuhan bawah berkaitan erat dengan kondisi habitat. Faktor lingkungan yang akan mempengaruhi keberadaan pertumbuhan adalah ketinggian tempat di atas permukaan laut. Ketinggian tempat akan mempengaruhi kekayaan jenis, struktur dan komposisi vegetasi tumbuhan bawah, keadaan tanah, suhu, intensitas cahaya dan air. Ketinggian tempat secara tidak langsung akan berperan dalam proses fotosintesis serta akan menjadi faktor pembatas yang akan menghambat pertumbuhan tumbuhan bawah (Wijayanti, 2011).

Menurut Juanda \& Cahyono (2005), suatu wilayah berdasarkan perbedaan ketinggian tempat dapat dibedakan menjadi 3, yaitu: daerah dataran rendah yang memiliki ktinggian tempat $0-200 \mathrm{~m} \mathrm{dpl}$, daerah dataran sedang yang memiliki ketinggian tempat 200$700 \mathrm{~m} \mathrm{dpl}$, dan daerah dataran tinggi yang memiliki ketinggian tempat di atas $700 \mathrm{~m} \mathrm{dpl}$.

Lokasi penelitian dilakukan pada tegakan pinus di Resort Pemangkuan Hutan (RPH) Kalirajut yang mewakili wilayah dataran rendah dan RPH Baturraden yang mewakili wilayah dataran tinggi. Kedua RPH tersebut termasuk ke dalam wilayah Kesatuan Pemangkuan Hutan (KPH) Banyumas Timur. 
Perbedaan ketinggian tersebut akan mempengaruhi faktor lingkungan yang lainnya, seperti suhu, kelembaban, intensitas cahaya, dan $\mathrm{pH}$ tanah yang akan menyebabkan berbeda pula kehadiran vegetasi tumbuhan bawahnya.

Berdasarkan uraian diatas tujuan dari penelitian ini adalah mengetahui struktur dan komposisi tumbuhan bawah tegakan Pinus pada ketinggian yang berbeda di KPH Banyumas Timur dan mengetahui kesamaan jenis tumbuhan bawah tegakan Pinus pada ketinggian yang berbeda di RPH Kalirajut dan RPH Baturraden, KPH Banyumas Timur.

\section{MET ODE}

Bahan yang digunakan dalam penelitian ini adalah berbagai jenis tumbuhan bawah pada tegakan Pinus di RPH Kalirajut dan RPH Baturraden. Alat yang digunakan adalah patok, tali rafia, meteran, kantong plastik, label, gunting, buku lapangan, alat tulis, soiltester, luxmeter, Global Positioning System (GPS), thermohigrometer, dan kamera

Metode yang digunakan dalam penelitian ini adalah metode survei dengan menggunakan petak kuadrat secara sistematis. Petak kuadrat yang digunakan berukuran $2 \times 2 \mathrm{~m}$ sebanyak 30 petak pada masing-masing lokasi penelitian. Dilakukan pengambilan sampel vegetasi tumbuhan bawah kemudian dicatat, dihitung dan didokumentasikan, setelah itu dlakukan pengukuran faktor lingkungan, identifikasi jenis tumbuhan bawah dengan menggunakan buku Sastrapradja $(1979,1980,1981,1985)$, Heyne (1987), dan Steenis (1972, 1981), kemudian dilakukan analisis data menggunakan Indeks Nilai Penting (INP), Indeks Kesamaan Komunitas (IS), Indeks Keanekaragaman ( $\left.\mathrm{H}^{\prime}\right)$ dan Indeks Kemerataan Jenis $(e)$.

\section{HASIL DAN PEMBAHASAN}

Komposisi vegetasi tumbuhan bawah pada tegakan pinus di RPH Kalirajut sebanyak 32 jenis dari 17 famili yang dari perdu ( 9 jenis), herba (13 jenis), rumput ( 7 jenis), dan paku (3 jenis). Famili tumbuhan yang banyak ditemukan dari lokasi yang diamati adalah tumbuhan dari famili Poaceae (Tabel 1). Famili Poaceae memiliki jumlah jenis tertinggi pada lokasi penelitian karena semua anggota famili ini merupakan tumbuhan yang mudah hidup pada berbagai habitat. Menurut Rukmana dan Saputra (1999) famili Poaceae memiliki daya adaptasi yang sangat tinggi, distribusi yang luas, dan mampu tumbuh pada lahan kering maupun tergenang.

Jenis tumbuhan bawah yang memiliki indeks nilai penting tertinggi di RPH Kalirajut adalah Ottochloa nodosa (31,58\%), Oplismenus compositus (12,29\%), dan Eleusine indica $(9,97 \%)$ (Tabel 1). Ketiga jenis tumbuhan bawah ini termasuk ke dalam famili Poaceae. Ewusie (1990) menyatakan bahwa terdapat berbagai macam karakteristik lingkungan tempat tumbuh tumbuhan dari famili Poaceae, baik lingkungan yang lembab maupun lingkungan yang kering. Karakter paling spesifik dari jenis tumbuhan famili Poaceae adalah kebutuhannya akan sinar matahari langsung dengan intensitas yang tinggi untuk dapat tumbuh dan berkembang biak dengan baik. Hal ini sesuai dengan hasil penelitian yang didapatkan bahwa intensitas cahaya pada RPH Kalirajut lebih tinggi yang memungkinkan jenis-jenis tersebut dapat hidup dengan baik dan tersebar luas.

Tingginya nilai INP mengartikan bahwa suatu jenis tersebut merupakan dominan dan mempunyai daya adaptasi yang lebih baik dari jenis lainnya. Menurut Lubis (2009), suatu jenis vegetasi dapat berpengaruh terhadap kestabilan ekosistem karena bersifat dominan dari jenis lainnya. Indeks Nilai Penting (INP) menunjukkan peranan jenis tersebut dalam suatu kawasan. Jenis yang mempunyai INP paling besar berarti mempunyai peranan yang paling penting di dalam kawasan tersebut. Jenis ini mempunyai pengaruh paling dominan terhadap perubahan kondisi lingkungan maupun keberadaan jenis lainnya dalam kawasan tersebut (Abdiyani, 2008).

Indeks keanekaragaman vegetasi tumbuhan bawah di wilayah dataran rendah (RPH Kalirajut) memiliki nilai sebesar 1,269. Nilai ini menunjukkan bahwa jumlah jenis diantara jumlah total individu seluruh jenis yang ada termasuk dalam kategori sedang. Kategori tersebut mengartikan bahwa komunitas sedang menuju pada kondisi yang stabil. Miardini et al., (2010), menyatakan bahwa nilai $\mathrm{H}^{\prime} 1 \leq$ $\mathrm{H}^{\prime} \leq 3$ menunjukkan bahwa keanekaragaman jenis pada suatu kawasan adalah sedang, penyebaran jumlah individu tiap jenis sedang dan kestabilan komunitas sedang. Tinggi rendahnya nilai indeks keanekaragaman suatu jenis dipengaruhi oleh banyaknya jenis dan jumlah individu yang ditemukan. Menurut Samingan (1976) makin banyak jenis yang ditemukan maka akan semakin tinggi nilai indeks keanekaragamannya. Semakin tinggi nilai keanekaragaman suatu kawasan menunjukkan semakin stabil komunitas di kawasan tersebut.

Indeks kemerataan di RPH Kalirajut tergolong tinggi yaitu sebesar 0,79. Menurut Magurran (1988) apabila indeks kemerataan lebih besar dari 0,6 maka sebaran individu antar jenis dapat dikatakan merata dan apabila indeks kemerataan kurang dari 0,6 maka sebaran individu antar jenis tidak merata atau terjadi dominansi suatu jenis. Komposisi vegetasi tumbuhan bawah di RPH Baturraden diperoleh sebanyak 19 jenis tumbuhan bawah yang termasuk ke dalam 11 famili yang terdiri dari perdu ( 6 jenis), herba ( 3 jenis), rumput ( 7 jenis), dan paku (3 jenis). Seperti pada lokasi RPH Kalirajut, famili tumbuhan bawah yang banyak ditemukan pada lokasi RPH Baturraden yaitu famili dari Poaceae (Tabel 2).

Wedelia trilobata merupakan tumbuhan terna musiman (herba) dengan panjang batang mencapai satu meter. $W$. trilobata memiliki daya adaptasi yang luas namun tumbuh dan berkembang dengan baik di bawah sinar matahari yang cukup serta dengan kondisi tanah yang cukup lembab (Syah et al., 2014). Paspalum conjugatum merupakan salah satu tumbuhan yang berasal dari Amerika. Jenis ini berkembang biak melalui biji dan juga akar rimpang, namun penyebaran melalui biji lebih berpotensi karena $P$. conjugatum memiliki biji yang cukup 
banyak. $P$. conjugatum dapat berkembang biak dengan baik di kondisi yang memiliki intensitas cahaya matahari dan kelembaban udara yang cukup yang memungkinkan jenis ini untuk berkecambah (Binibis, 2014). Clidemia hirta berbunga sepanjang tahun, tumbuhan ini berasal dari Amerika Selatan, sifatnya menyebar dengan cepat dan lebih melimpah di luar daerah asalnya dibanding habitat aslinya. C. hirta merupakan jenis tumbuhan bawah yang memiliki daya adaptasi tinggi karena mampu tumbuh secara optimal pada ketinggian rendah hingga mencapai $1000 \mathrm{~m}$ dpl dengan kondisi lingkungan yang terbuka dan lembab serta tanah yang memiliki kandungan humus yang tinggi (Ismaini, 2015).

Tabel 1. Jenis tumbuhan bawah yang ditemukan di RPH Kalirajut

\begin{tabular}{|c|c|c|c|c|c|c|}
\hline No. Nama Jenis & Famili & $\mathbf{K}$ & KR (\%) & $\mathbf{F}$ & FR (\%) & INP (\%) \\
\hline 1. Ottochloa nodosa & Poaceae & 9,24 & 26,24 & 0,83 & 5,34 & 31,58 \\
\hline 2. Oplismenus compositus & Poaceae & 2,90 & 8,23 & 0,63 & 4,05 & 12,29 \\
\hline 3. Eleusine indica & Poaceae & 2,15 & 6,12 & 0,60 & 3,84 & 9,97 \\
\hline 4. Clidemia hirta & Melastomataceae & 1,27 & 3,62 & 0,86 & 5,55 & 9,17 \\
\hline 5. Pteris ensiformis & Pteridaceae & 1,51 & 4,30 & 0,70 & 4,48 & 8,79 \\
\hline 6. Acalypta indica & Euphorbiaceae & 1,68 & 4,78 & 0,60 & 3,84 & 8,62 \\
\hline 7. Abrus precatorus & Fabaceae & 1,25 & 3,57 & 0,56 & 3,63 & 7,20 \\
\hline 8. Panicum repans & Poaceae & 1,18 & 3,36 & 0,56 & 3,63 & 6,99 \\
\hline 9. Cyrtococcum acrescens & Poaceae & 1,18 & 3,36 & 0,53 & 3,41 & 6,77 \\
\hline 10. Centrosema pubescens & Fabaceae & 0,83 & 2,36 & 0,66 & 4,27 & 6,63 \\
\hline 11. Angiopteris avecta & Marattiaceae & 0,92 & 2,62 & 0,60 & 3,84 & 6,47 \\
\hline 12. Paspalum conjugatum & Poaceae & 1,20 & 3,40 & 0,43 & 2,77 & 6,18 \\
\hline 13. Pteris vittata & Pteridaceae & 0,90 & 2,55 & 0,50 & 3,20 & 5,76 \\
\hline 14. Fimbristylis miliacea & Cyperaceae & 0,65 & 1,84 & 0,60 & 3,84 & 5,69 \\
\hline 15. Melastoma polyanthum & Melastomataceae & 0,53 & 1,51 & 0,60 & 3,84 & 5,36 \\
\hline 16. Eragrotis amabilis & Poaceae & 0,68 & 1,94 & 0,50 & 3,20 & 5,14 \\
\hline 17. Molineria capitulata & Hypoxidaceae & 0,72 & 2,05 & 0,46 & 2,99 & 5,05 \\
\hline 18. Colocasia esculenta & Araceae & 0,65 & 1,86 & 0,46 & 2,99 & 4,86 \\
\hline 19. Kyllinga monocephala & Cyperaceae & 0,61 & 1,75 & 0,43 & 2,77 & 4,52 \\
\hline 20. Mikania micrantha & Asteraceae & 0,50 & 1,44 & 0,43 & 2,77 & 4,22 \\
\hline 21. Oxalis barrelieri & Oxalidaceae & 0,50 & 1,44 & 0,43 & 2,77 & 4,22 \\
\hline 22. Selaginella wildenowii & Selaginellaceae & 1,25 & 3,57 & 0,43 & 2,77 & 4,19 \\
\hline 23. Diplazium proliferum & Athyriaceae & 0,33 & 0,94 & 0,50 & 3,20 & 4,15 \\
\hline 24. Cheilocostus speciosus & Costaceae & 0,55 & 1,56 & 0,40 & 2,56 & 4,12 \\
\hline 25. Ageratum conyzoides & Asteracea & 0,52 & 1,49 & 0,36 & 2,35 & 3,84 \\
\hline 27. Elephantopus scaber & Asteraceae & 0,39 & 1,11 & 0,33 & 2,13 & 3,24 \\
\hline 26. Ficus septica & Moraceae & 0,18 & 0,52 & 0,40 & 2,56 & 3,08 \\
\hline 28. Pisonia excels & Nyctaginaceae & 0,14 & 0,40 & 0,33 & 2,13 & 2,53 \\
\hline 29. Gynura procumbens & Asteraceae & 0,24 & 0,68 & 0,26 & 1,70 & 2,39 \\
\hline 30. Urena trifolia & Poaceae & 0,28 & 0,80 & 0,23 & 1,49 & 2,30 \\
\hline 31. Cyrtococcum trigonum & Poaceae & 0,10 & 0,30 & 0,16 & 1,06 & 1,37 \\
\hline 32. Ananas comosus & Bromeliaceae & 0,06 & 0,18 & 0,13 & 0,85 & 1,04 \\
\hline Jumlah & & 35,21 & 100 & 15,60 & 100 & 200 \\
\hline
\end{tabular}

Tabel 2. Tumbuhan bawah yang ditemukan di RPH Baturraden

\begin{tabular}{|c|c|c|c|c|c|c|}
\hline No. Nama Jenis & Famili & $\mathbf{K}$ & KR (\%) & $\mathbf{F}$ & FR (\%) & INP (\%) \\
\hline 1. Wedelia trilobata & Asteraceae & 23,35 & 54,48 & 1,00 & 15,62 & $\mathbf{7 0 , 1 0}$ \\
\hline 2. Paspalum conjugatum & Poaceae & 7,75 & 18,08 & 0,86 & 13,54 & 31,61 \\
\hline 3. Clidemia hirta & Melastomataceae & 1,12 & 2,62 & 0,60 & 9,37 & 11,99 \\
\hline 4. Panicum repans & Poaceae & 1,01 & 2,37 & 0,43 & 6,77 & 9,14 \\
\hline 5. Molineria capitulata & Hypoxidaceae & 0,80 & 1,88 & 0,43 & 6,77 & 8,65 \\
\hline 6. Eragrotis amabilis & Poaceae & 0,51 & 1,20 & 0,46 & 7,29 & 8,49 \\
\hline 7. Dryopteris filix-mas & Dryopteridaceae & 0,57 & 1,34 & 0,43 & 6,77 & 8,11 \\
\hline 8. Axonopus compressus & Poaceae & 2,31 & 5,40 & 0,13 & 2,08 & 7,48 \\
\hline 9. Eleusine indica & Poaceae & 1,60 & 3,73 & 0,23 & 3,64 & 7,37 \\
\hline 10. Ottochloa nodosa & Poaceae & 1,15 & 2,68 & 0,30 & 4,68 & 7,36 \\
\hline 11. Nephrolepis hirsutula & Dryopteridaceae & 0,88 & 2,06 & 0,30 & 4,68 & 6,74 \\
\hline 12. Melastoma polyanthum & Melastomataceae & 0,39 & 0,91 & 0,30 & 4,68 & 5,60 \\
\hline 13. Abrus precatorus & Fabaceae & 0,17 & 0,40 & 0,23 & 3,64 & 4,05 \\
\hline 14. Astilbe rivularis & Saxifragaceae & 0,25 & 0,60 & 0,20 & 3,12 & 3,72 \\
\hline 15. Selaginella wildenowii & Selaginellaceae & 0,25 & 0,58 & 0,16 & 2,60 & 3,18 \\
\hline 16. Digitaria ciliaris & Poaceae & 0,37 & 0,87 & 0,06 & 1,04 & 1,91 \\
\hline 17. Hedyotis vestita & Rubiaceae & 1,10 & 0,25 & 0,10 & 1,56 & 1,81 \\
\hline 18. Rubus rosaefolius & Rosaceae & 0,15 & 0,35 & 0,06 & 1,04 & 1,39 \\
\hline 19. Eupatorium riparium & Arecaceae & 0,06 & 0,15 & 0,06 & 1,04 & 1,19 \\
\hline Jumlah & & 42,87 & 100 & 6,40 & 100 & 200 \\
\hline
\end{tabular}


Palijama et al. (2012) menyatakan bahwa, kondisi pH tanah, kelembaban tanah serta intensitas cahaya sangat mendukung $C$. hirta untuk dapat tumbuh dengan cepat. Tanasale (2010) melanjutkan bahwa, $C$. hirta memiliki daun yang lebar sehingga lebih banyak menyerap unsur $\mathrm{N}$ dan lebih banyak menggunakan air yang menyebabkan pertumbuhannya lebih cepat. Hal ini menyebabkan $C$. hirta ditemukan di kedua lokasi dengan nilai INP yang cukup tinggi yaitu $9,17 \%$ pada RPH Kalirajut dan 11,99\% pada RPH Baturraden yang berarti kedua lokasi penelitian tersebut merupakan tempat tumbuh yang cocok bagi jenis $C$. hirta sehingga dapat tumbuh dengan cepat.

Indeks Nilai Penting (INP) menunjukkan peranan jenis tersebut dalam suatu kawasan. Jenis yang mempunyai INP paling besar berarti mempunyai peranan yang paling penting di dalam kawasan tersebut. Jenis ini mempunyai pengaruh paling dominan terhadap perubahan kondisi lingkungan maupun keberadaan jenis lainnya dalam kawasan tersebut (Abdiyani, 2008). Menurut Sofyan (1991), jenis yang mempunyai indeks nilai penting tertinggi diantara jenis yang lain disebut jenis yang dominan. Hal ini mencerminkan tingginya kemampuan jenis tersebut dalam menyesuaikan diri dengan lingkungan yang ada dan dapat bersaing terhadap jenis lainnya.

Indeks keanekaragaman Shannon-Wiener pada RPH Baturraden yaitu sebesar 0,73. Berdasarkan klasifikasi Barbour (1987) dalam Prasetyo (2007), indeks keanekaragaman di RPH Baturraden masih tergolong rendah. Keadaan tersebut terjadi disebabkan adanya variasi faktor lingkungan yang berbeda. Menurut Kartasapoetra (1992), faktorfaktor lingkungan yang sangat berpengaruh terhadap vegetasi diantaranya adalah ketinggian tempat, kelembaban udara, suhu udara serta intensitas cahaya matahari. Faktor-faktor lingkungan tersebut berpengaruh terhadap penyebaran jenis-jenis tumbuhan dan pertumbuhannya.

Indeks kemerataan pada RPH Baturraden berbeda dengan nilai indeks kemerataan yang ada pada RPH Kalirajut, yaitu sebesar 0,57. Nilai ini dikatakan dalam golongan yang sedang. Menurut Mawazin \& Subiakto (2013), semakin tinggi nilai $e$, maka semakin stabil keanekaragaman jenisnya .

Indeks kesamaan (IS) diperlukan untuk mengetahui tingkat kesamaan pada tegakan yang dibandingkan. Oleh karena itu, besar kecilnya nilai indeks kesamaan tersebut memperlihatkan tingkat kesamaan dari tegakan yang dibandingkan. Krebs (1985), menyatakan semakin besar nilai IS maka jenis yang sama pada tegakan yang dibandingkan semakin banyak. Indeks kesamaan jenis Sorensen pada tegakan pinus di RPH Kalirajut dan RPH Baturraden adalah sebesar 30,85\%. Nilai ini menunjukkan bahwa komposisi jenis di dataran rendah yaitu RPH Kalirajut dan dataran tinggi yaitu RPH Baturraden relatif berbeda. Besar kecilnya nilai indeks kesamaan komunitas tumbuhan dipengaruhi oleh jumlah individu dari jenis yang sama antar dua komunitas yang dibandingkan. Semakin banyak jenis tumbuhan yang sama antar dua komunitas yang dibandingkan maka indeks kesamaan komunitasnya akan semakin besar.

Perbedaan komunitas terjadi disebabkan oleh adanya perbedaan faktor lingkungan yang berbeda pada kedua lokasi. Hasil pengukuran faktor lingkungan di RPH Kalirajut dan RPH Baturraden menunjukkan hasil yang relatif berbeda.

Tabel 3. Faktor lingkungan pada lokasi penelitian

\begin{tabular}{|c|c|c|}
\hline $\begin{array}{l}\text { Faktor } \\
\text { Lingkungan }\end{array}$ & $\begin{array}{r}\text { RPH } \\
\text { Kalirajut }\end{array}$ & $\begin{array}{r}\text { RPH } \\
\text { Baturraden }\end{array}$ \\
\hline Suhu udara & $28^{\circ} \mathrm{C}-31^{\circ} \mathrm{C}$ & $23^{\circ} \mathrm{C}-26^{\circ} \mathrm{C}$ \\
\hline Intensitas cahaya & $15.430-16.540$ lux & $14.250-16.100$ lux \\
\hline Kelembaban udara & $38 \%-41 \%$ & $60 \%-64 \%$ \\
\hline $\mathrm{pH}$ tanah & $4,5-5,0$ & $5,5-6,0$ \\
\hline
\end{tabular}

Suhu lingkungan di RPH Kalirajut sebesar $28-31^{\circ} \mathrm{C}$, sedangkan di RPH Baturraden berkisar antara 23$26^{\circ} \mathrm{C}$ (Tabel 3). Menurut Goltenboth et al. (2006), perbedaan ketinggian tempat menyebabkan terjadinya perbedaan suhu lingkungan. Suhu lingkungan merupakan salah satu faktor penting karena mempunyai pengaruh terhadap proses metabolisme dan susunan vegetasi tumbuhan bawah. Tumbuhan memerlukan suhu $15-25^{\circ} \mathrm{C}$ untuk tumbuh optimal, apabila suhu terlalu tinggi atau rendah akan menyebabkan tumbuhan tersebut mati (Arief, 1994).

Salah satu faktor penentu temperatur adalah intensitas cahaya. Rata-rata intensitas cahaya pada tegakan Pinus di RPH Kalirajut yaitu berkisar antara 15.430-16.540 lux sedangkan pada tegakan Pinus di RPH Baturraden yaitu berkisar antara 14.250-16.100 lux (Tabel 3). Intensitas cahaya merupakan sumber energi dalam proses fotosintesis untuk memproduksi tepung/karbohidrat dan oksigen. Intensitas cahaya yang rendah akan mempengaruhi proses fotosintesis yang akan menyebabkan produktivitasnya menjadi rendah (Nahdi \& Darsikin, 2014). Hal ini sesuai dengan hasil yang didapatkan bahwa intensitas cahaya pada RPH Baturraden lebih rendah dibandingkan RPH Kalirajut yang memiliki keanekaragaman jenis tumbuhan bawah lebih sedikit.

Hasil pengukuran kelembaban udara di RPH Kalirajut berkisar antara 38-41\%, sedangkan di RPH Baturraden adalah 60-64\% (Tabel 3). Balai Taman Nasional Baluran (2000) menyatakan bahwa, kelembaban yang terlalu tinggi akan menghambat proses transpirasi pada tumbuhan yang berakibat terhambatnya penyerapan air dan garam mineral dari dalam tanah oleh tumbuhan. Hal ini sesuai dengan hasil yang didapatkan bahwa tumbuhan bawah yang ditemukan pada RPH Baturraden lebih sedikit yaitu sebanyak 19 jenis, sedangkan pada RPH Kalirajut yaitu sebanyak 32 jenis tumbuhan bawah.

Pengukuran $\mathrm{pH}$ tanah pada kedua lokasi menunjukkan hasil yaitu 4,5-5,0 pada RPH Kalirajut dan 5,5-6,0 pada RPH Baturraden (Tabel 3). Menurut Sandoval \& Rodriguez (2008), jenis Wedelia trilobata menyukai lingkungan dengan $\mathrm{pH}$ tanah berkisar 
5,5-6,5 atau sedikit asam cenderung netral. Hal ini sesuai dengan hasil yang didapatkan bahwa jenis $W$. trilobata ditemukan banyak RPH Baturraden yang memiliki $\mathrm{pH}$ tanah sesuai bagi pertumbuhan dan perkembangbiakannya. Menurut Hakim et al. (1986), semakin tingginya $\mathrm{pH}$ tanah maka keragaman jenisnya akan semakin rendah yang disebabkan karena semakin tingginya $\mathrm{pH}$ ketersediaan asamasam tertentu akan semakin berkurang. Hal ini juga sesuai dengan hasil yang didapatkan bahwa $\mathrm{pH}$ pada RPH Kalirajut memiliki pH yang lebih rendah dan memiliki keragaman jenis yang lebih tinggi dibandingkan dengan RPH di Baturraden.

\section{KESIMPULAN DAN SARAN}

Hasil penelitian ini dapat disimpulkan bahwa: jumlah jenis tumbuhan bawah yang ditemukan di RPH Kalirajut yaitu 32 jenis yang terdiri dari 17 famili, sedangkan di RPH Baturraden yaitu 19 jenis yang terdiri dari 11 famili; dan jenis tumbuhan yang memiliki nilai penting tertinggi di RPH Kalirajut yaitu Ottochloa nodosa, Oplismenus compositus, dan Eleusine indica, sedangkan jenis tumbuhan yang memiliki indeks nilai penting tertinggi di RPH Baturraden yaitu Wedelia trilobata, Paspalum conjugatum, dan Clidemia hirta; serta kesamaan jenis tumbuhan bawah pada tegakan Pinus antara RPH Kalirajut dengan RPH Baturraden tergolong berbeda.

Perlu dilakukan penelitian secara periodik, agar dapat memberikan gambaran dinamika komposisi tumbuhan bawah di RPH Kalirajut dan RPH Baturraden. Selain itu komposisi yang tercatat diharapkan menjadi informasi agar tumbuhan bawah yang memiliki manfaat dan nilai ekonomi tinggi dapat terjaga dengan baik.

\section{AF T AR REFERENSI}

Abdiyani S. 2008. Keanekaragaman jenis tumbuhan bawah berkhasiat obat di Dataran Tinggi Dieng. Jurnal Penelitian Hutan dan Konservasi Alam. 1 (5):79-92.

Arief A. 1994. Hutan alam dan pengaruh terhadap lingkungannya. Jakarta: Yayasan Obor.

Backer CA. 1973. Weed Flora of Javanese sugar-cane fields. Deventer:Ysel Press.

Balai Taman Nasional Baluran. 2000. Laporan pelaksanaan kegiatan sarasehan peningkatan peran serta masyarakat terhadap pengamanan hutan. Banyuwangi: Departemen Kehutanan RI.

Binibis L. 2014. Inventarisasi tumbuhan bawah di kawasan penambangan emas Desa Juria Kecamatan Bilato Kabupaten Gorontalo [tesis]. Universitas Gorontalo.

Ewusie JY. 1990. Ekologi tropika. Bandung: ITB.

Goltenboth F, Timotius KH, Milan PO, Margraf J. 2006. Ecology of Insular South East Asia The Indonesia Archipelago $1^{\text {st }}$ Edition. Elsevier B. V. The Nederlands.

Hakim N, Nyakpa MY, Nugroho SGB, Barley HH. 1986. Dasar dasar Ilmu Tanah. Lampung: Universitas Lampung.

Hilwan I, Mulyana D, Pananjung WD. 2013. Keanekaraaman jenis tumbuhan bawah pada Tegakan Sengon Buto (Enterolobium cyclocarpum Griseb.) dan Trembesi (Samanea saman Merr.) di Lahan Pasca Tambang Batubara PT Kitadin, Embalut, Kutai Kartanagara Kalimantan Timur. Jurnal Silvikultur Tropika, 4(1):6-10.

Heyne K. 1987. Tumbuhan berguna Indonesia (Terjemahan) Jilid III. Jakarta: Badan Penelitian dan Pengembangan Kehutanan.
Ismaini L. 2015. Pengaruh alelopati tumbuhan invasif (Clidemia hirta) terhadap germinasi biji tumbuhan asli (Impatiens platypetala). Pros Sem Nas Masy Biodiv Indon 1(4):834-837.

Juanda DJS, Cahyono B. 2005. Teknik budidaya dan analisis usaha tani. Yogyakarta: Kanisius.

Kartasapoetra G. 1992. Budidaya tanaman berkhasiat obat : kunyit (kunir). Jakarta: PT. Rineka Cipta.

Krebs CJ. 1985. Ecology: The experimental analysis of distribution and abundance. New York: Harper \& Row, INC.

Lubis SR. 2009. Keanekaragaman dan pola distribusi tumbuhan paku di Hutan Wisata Alam Taman Eden Kabupaten Toba Samosir Provinsi Sumatera Utara. Medan: Pascasarjana Universitas Sumatera Utara.

Magurran AE. 1988. Ecological diversity and its measurement. USA: Chapman and Hall.

Mawazin, Subiakto A. 2013. Keanekaragamandan komposisi jenis permudaan alam hutan rawa gambut bekas tebangan di Riau. Forest Rehabilitation. 1(1):59-73.

Miardini A, Boediyono A, Atmoko BD, Harjadi B, Gunawan. 2010. Analisis kerentanan tumbuhan hutan akibat perubahan iklim. Solo: Badan Penelitian dan Pengembangan Hutan.

Mueller D, Ellenberg H. 1974. Aims and methods of vegetation ecology. New York: Wiley International Edition.

Nahdi MS, Darsikin. 2014. Distribusi dan kemelimpahan jenis tumbuhan bawah pada naungan Pinus mercusii, Acasia auriculiformis dan Eucalyptus alba di Hutan Gama Giri Mandiri Yogyakarta. Jurnal Natur Indonesia.16(1):33-41.

Nirwani Z. 2010. Keanekaragaman tumbuhan bawah yang berpotensi sebagai tanaman obat di Hutan Taman Nasional Gunung Leuser Sub Seksi Bukit Lawang [skripsi]. Fakultas Kehutanan Universitas Negeri Sumatera Utara.

Palijama W, Riry J, Wattimena AY. 2012. Komunitas gulma pada pertanaman pala (Myristica fragrans $\mathrm{H}$ ) belum menghasilkan dan menghasilkan di Desa Hutumuri Kota Ambon. Agrologia. 1 (2):91-169.

Prasetyo B. 2007. Keanekaragaman tanaman buah di pekarangan Desa Jabon Mekar Kecamatan Parung Bogor [skripsi] Jurusan Biologi. FMIPA. Tangerang: Universitas Terbuka.

Rukmana HR, Saputra US. 1999. Gulma dan teknik pengendalian. Jakarta: Kanisius.

Samingan T. 1976. Pemantaran metode pendugaan hasil potensi hutan dalam rangka kelestarian pemungutan hasil hutan. Buletin PERSAKI. 8 (I) :3- 9.

Sandoval JR, Rodríguez PA. 2008. Department of Botany. USA: Smithsonian NMNH.

Sastrapradja S, Afriastini JJ. 1979. Jenis Paku Indonesia. Bogor: Lembaga Biologi Nasional, Lembaga Ilmu Pengetahuan Indonesia.

Sastrapradja S, Afriastini JJ. 1980. Jenis rumput dataran rendah. Bogor: Lembaga Biologi Nasional, Lembaga Ilmu Pengetahuan Indonesia.

Sastrapradja S, Afriastini JJ. 1981. Rumput pegunungan. Bogor: Lembaga Biologi Nasional, Lembaga Ilmu Pengetahuan Indonesia.

Sastrapradja S, Afriastini JJ. 1985. Kerabat Paku. Bogor: Lembaga Biologi Nasional, Lembaga Ilmu Pengetahuan Indonesia.

Soerianegara I, Indrawan A. 2005. Ekosistem Hutan Indonesia. Bogor: Laboratorium Ekologi Hutan Fakultas Kehutanan IPB.

Sofyan MZ. 1991. Analisis vegetasi pohon di Hutan Saloguma [skripsi]. Padang: Fakultas Matematika dan Ilmu Pengetaguan Alam Universitas Andalas

Steenis CGGJ Van. 1972. The mountain flora of Java. Leiden: E.J. Brill.

Steenis CGGJ Van. 1981. Flora: Untuk sekolah di Indonesia. Jakarta: PT. Pradanya Paramita.

Syah AS, Sulaeman SM, Pitopang R. 2014. Jenis-jenis tumbuhan Suku Asteraceae di Desa Mataue, Kawasan Taman Nasional Lore Lindu. Online Jurnal of Natural Science. 3(3):297 - 312.

Tanasale V. 2010. Komunitas gulma pada pertanaman gandaria belum menghasilkan dan menghasilkan pada ketinggian tempat yang berbeda [tesis]. Yogyakarta: Universitas Gadjah Mada.

Wijayanti YE. 2011. Struktur dan komposisi komunitas tumbuhan lantai Hutan di Kawasan Cagar Alam Ulolong Kecubung Kecamatan Subah Kabupaten Batang [skripsi].IKIP PGRI Semarang Fakultas Pendidikan Matematika dan Ilmu Pengetahuan Alam Jurusan Pendidikan Biologi. 
Windusari Y. 2012. Dugaan cadangan karbon biomassa tumbuhan bawah dan serasah di Kawasan Suksesi Alami pada area pengendapan Tailing PT. Freeport Indonesia. Sumatra Selatan. Biospecies. 5(1): 22-28.

Wirakusuma RS. 1980. Citra dan fenomena Hutan Tropika Humida Kalimantan Timur. Jakarta: Pradya Paramita.
Yuniawati. 2013. Pengaruh pemanenan kayu terhadap potensi karbon tumbuhan bawah dan serasah di lahan Gambut (Studi Kassus di Areal HTI Kayu Serat PT. RAPP Sektor Pelalawan). Propinsi Riau. Hutan Tropis. 1(1)2337-7771. 